\title{
IL-15 negatively regulates curdlan-induced IL-23 production by human monocyte-derived dendritic cells and subsequent Th17 response
}

\author{
(D) Ahmet Eken, ${ }^{1}$ (D) Fatma Zehra Okus, ${ }^{1}$ (D) Serife Erdem, ${ }^{1}$ (D) Zehra Busra Azizoglu, ${ }^{1}$ (D) Yesim Haliloglu, ${ }^{1}$ \\ Ayten Bicer, ${ }^{1}$ (D) Tugba Nur Gur, ${ }^{1}$ (D) Ebru Yilmaz, ${ }^{2}$ (D) Musa Karakukcu, ${ }^{2}$ (i) Hamiyet Donmez Altuntas, ${ }^{1}$ \\ (D) Halit Canatan ${ }^{1}$ \\ ${ }^{1}$ Department of Medical Biology, Erciyes University Faculty of Medicine, Betül-Ziya Eren Genome and Stem Cell Center (GENKOK), Kayseri, Turkey \\ ${ }^{2}$ Department of Pediatric Hematology-Oncology, Erciyes University Faculty of Medicine, Kayseri, Turkey
}

\begin{abstract}
OBJECTIVE: In this study, we aimed to assess the effects of long- and short-term IL-15 cytokine exposure of human monocyte-derived curdlan-matured dendritic cells (DCs) on the production of Th17 cell-polarizing cytokine IL-23 and subsequent Th17 cell activation.

METHODS: Peripheral blood mononuclear cells (PBMCs) were purified using Ficoll-Paque from healthy donors. Monocytes were magnetically selected using CD14 Miltenyi beads and differentiated into DCs with granulocyte-macrophage colony-stimulating factor (GM-CSF) and IL-4 for five days in the presence or absence of IL-15 (100ng/ml) for long-term exposure experiments. Then, DCs were matured with peptidoglycan (PGN), or curdlan for 24 hours. For short-term exposure experiments, IL-15 was added only during maturation of DCs. Then, DCs were characterized concerning the expression of MHC II and costimulatory molecules, production of cytokine subunits IL-23p19, IL-12p40, IL-12p35 and cytokine IL-23 via flow cytometry or real-time qPCR or ELISA. Finally, the phosphorylation of signaling molecules after curdlan stimulation was assessed using phospho-flow assays.
\end{abstract}

RESULTS: IL-15 exposure suppressed IL-23 production by DCs. As a result, IL-15-exposed DCs suppressed IL-17 production by allogeneic T cells. Importantly, we observed a reduction in the surface Dectin-1 receptor levels by IL-15-exposed DCs. In line with these observations, curdlan stimulation resulted in reduced phosphorylation of ERK1/2, NF-kB p65 and AKT by human DCs exposed to IL-15 compared with controls. These results may explain why IL-15-exposed DCs produce less IL-23 after maturation with curdlan, which is a ligand of Dectin-1.

CONCLUSION: Short- or long-term exposure to IL-15 of human DCs during their differentiation or maturation programs DCs against Th17 cell polarization, which suggests that IL-15 availability may affect CD4+ T cell-mediated protective immunity to fungal infections.

Keywords: Dendritic cell; IL-15; Th17; IL-23.

Cite this article as: Eken A, Okus FZ, Erdem S, Azizoglu ZB, Haliloglu Y, Bicer A, et al. IL-15 negatively regulates curdlan-induced IL-23 production by human monocyte-derived dendritic cells and subsequent Th17 response. North Clin Istanb 2019;6(4):379-387.

Received: July 05, 2019 Accepted: August 19, 2019 Online: October 24, 2019

Correspondence: Dr. Ahmet EKEN. Erciyes Universitesi Tip Fakultesi, Betul-Ziya Eren Genom ve Kok Hucre Merkezi (GENKOK), Tibbi Biyoloji Anabilim Dali, Kayseri, Turkey.

Tel: +90 3522076666 - 13671 e-mail: ahmet.eken@gmail.com

(c) Copyright 2019 by Istanbul Provincial Directorate of Health - Available online at www.northclinist.com 
Tnterleukin (IL)-15 is a $14-15 \mathrm{kD}$ cytokine that belongs to four alpha-helical bundle cytokines [1-5]. IL-15 is produced by antigen-presenting cells, such as dendritic cells (DCs) and monocytes; however, non-hematopoietic sources have also been identified $[1,3,6]$. T cells have been reported to produce IL-15 although this has not been repeated by another study [7]. IL-15 receptor is a heterotrimer composed of IL-15Ra, IL-2R $\beta / \mathrm{IL}$ $15 R \beta$ and IL-2Ryc. The common gamma chain is shared by several other cytokine receptors, including IL-2, IL4, IL-7, IL-9 and IL-21, whereas IL-15R $\beta$ subunit is shared by IL-2 receptor $[1,8,9]$. IL-15R signalling predominantly activates JAK1/JAK3 and STAT5/STAT3 $[1,2,9]$. IL-15 can complex with IL-15Ra, and this complex can signal to NK or T cells which lack IL-15Ra but express IL-2R $\beta /$ IL-15R $\beta$ and IL2R $\gamma c$ through a process called trans-presentation [10]. IL-15 has been shown to be critical in NK cell generation and survival of CD8+ memory $\mathrm{T}$ cells $[1,2,11,12]$.

IL-23 is a heterodimeric cytokine composed of a specific p19 (IL-23A) and a shared subunit p40 (IL-12B) $[13,14]$. IL-23 is produced mainly by antigen-presenting cells and over the last fifteen years have been shown to be critical in the pathogenesis of several autoimmune diseases, including multiple sclerosis (MS), inflammatory bowel diseases (IBD) and rheumatoid arthritis $[15,16]$. IL-23 was shown to activate both innate and adaptive immune cells. Pathogenic Th17 cells require IL-23 for their expansion and acquiring pathogenic character $[14$, $17,18]$. IL-23 production was shown to be induced by fungal and certain extracellular pathogens and -associated molecular patterns, such as $\beta$-glucan [14].

The potential effects of IL-15 on murine Th17 cell generation and function have been studied, and collectively the data mark IL-15 as a negative regulator of Th17 through its direct effects on T cells. Exogenous IL-15 or IL-2 addition was shown to limit Th17 generation and IL-17A production in culture [19-23]. IL-2-/- or IL-15-/- mice were shown to have elevated frequency of Th17 cells in the lamina propria. Importantly, IL-15-/ - mice developed more severe experimental autoimmune encephalomyelitis (EAE) with increased IL-17A in the serum. Additionally, IL-15Ra-deficient $\mathrm{T}$ cells produced more IL-17A and caused more severe colitis when ex vivo generated Th17 cells transferred into Rag1-/ - mice [19]. Inhibitory effects of IL-15 on IL-17A production was attributed to STAT5 binding to IL-17A regulatory regions [19]. Tosiek et al. also reported similar findings in mice, that is IL-15 suppressed Roryt expression, as such, when CD4+ T cells were transferred to lymphopenic IL-15-/ - hosts, they had elevated Roryt and IL-17A expression, and impaired Treg functions [22, 23]. Although IL-15 production by Th17 cells was reported by Pandiyan et al., others have shown that murine CD4+ T cells do not express IL-15, or IL15Ra, but express IL-2Ryc [7]. Therefore, IL-15 signaling in those cells may be mediated, to some extent, through IL-15Ra and IL-15 trans-presentation.

IL-15 may also reprogram murine or human dendritic cells; thus, indirectly regulate Th17 polarization or activity; however, evidence for this is scarce. In this regard, lamina propria DCs isolated from IL-15 transgenic mice showed reduced capacity to induce OVA323-339 (subscript) antigen-specific Th17 cells [20]. On the other hand, Anguille et al. and Harris et al. generated DCs from human monocytes with GM-CSF and IL-15, interestingly those DCs produced more IL-6, IL- $1 \beta$ and IL-23 [24-26]. These results are difficult to reconcile with the observations which show increased Th17 response in the absence of IL-15 or IL-15 signaling. Moreover, to our knowledge, how IL-15 exposure may affect the outcome of DC maturation in response to fungal pathogen-associated molecular patterns (PAMP) has not been assessed yet, which remained under-researched. Therefore, in this study, we aimed to investigate the impacts of a long term or short-term IL-15 exposure of human monocytederived DCs concerning IL-23 production and Th17 cell polarization. Our results reveal that IL-15 exposure results in reduced Dectin-1 receptor expression, which leads to impaired curdlan-mediated maturation, and IL23 production, subsequently reduced Th17 response.

\section{MATERIALS AND METHODS}

\section{Isolation of PBMCs and Monocytes}

Peripheral blood (10-15 cc) was drawn from healthy donors after obtaining their consent $(n=10)$. The study protocol was approved by the local ethics committee of Erciyes University (\#2015/521), and written informed consent was obtained from all donors. All experiments and protocols for human studies involving human samples were performed in accordance with the relevant guidelines and regulations. PBMCs were isolated via Ficoll-Paque (density $1.077 \mathrm{~g} / \mathrm{mL}$ ) density gradient according to the manufacturer's protocol (GE Healthcare \# GE17-1440-02). CD14+ monocytes were isolated using Miltenyi CD14 MicroBeads \#130-050-201 as described by the manufacturer. Cells were counted using Trypan Blue exclusion under a hemocytometer. 


\section{Differentiation}

Equal number of monocytes was cultured in 24 well plates in complete medium (RPMI 1640 (R8758$500 \mathrm{ML}$, Sigma) supplemented with $10 \% \mathrm{FBS}$, L-glutamine (Gibco, 25030081), essential (Gibco, 11130051) and non-essential (Gibco, 11140050) amino acids) containing $50 \mathrm{ng} / \mathrm{ml} \mathrm{IL-4} \mathrm{(BioLegend,} \mathrm{766202),} \mathrm{and} 50$ $\mathrm{ng} / \mathrm{ml} \mathrm{GM}$-CSF (BioLegend, 713604) for five days at 37C, 5\% CO2. For long-term IL-15 exposure, $100 \mathrm{ng} /$ $\mathrm{ml} \mathrm{IL-15} \mathrm{(BioLegend,} \mathrm{715902)} \mathrm{was} \mathrm{added} \mathrm{to} \mathrm{differen-}$ tiation cultures during differentiation for five days, and maturation (plus 24 hours). Then, cells were counted, and the equal number of DCs was matured with various ligands: peptidoglycan (PGN) $50 \mu \mathrm{g} / \mathrm{ml}$, curdlan $50 \mu \mathrm{g} /$ $\mathrm{ml}$, (both from InVivoGen) for 24 hours. For short-term exposure, $100 \mu \mathrm{g} / \mathrm{ml} \mathrm{IL-15}$ was added during maturation (24 hours), not differentiation.

Surface, Intracellular Staining and Phospho-flow Assays Surface staining was performed in round bottom 96-well plates. $2 \times 10^{4}$ cells were resuspended in $100 \mu$ l Staining Buffer (Phosphate Buffered Saline (PBS) supplemented with $2 \% \mathrm{FBS}$ ) and blocked with Fc-block (BioLegend) for 5 minutes. Then, antibodies were added according to manufacturer's dilution recommendation. After $30 \mathrm{~min}$ utes of incubation in dark and on ice, cells were washed with staining buffer twice, spun at $400 \mathrm{~g}$ for 2 times. Then, cells were resuspended in $200 \mu \mathrm{l}$ staining buffer and run on FACSAria III. Antibody list: APC-anti-human HLA-II (BioLegend, \#361713), Percp Cy5.5-anti-human CD11c (BioLegend, \#301623), FITC-antihuman CD80 (BioLegend, \#305206), PE-anti- human CD86 (BioLegend, \#374206), APC-anti- human IL17A (BioLegend, \#512334), PE-anti- human GM-CSF (BioLegend, \# 502306), APC Cy7-anti- human IFN-y (BioLegend, \#502530), anti- human CD3 (BioLegend, \# 300331), anti-human IL-15 Antibody (R\&D Systems, MAB247-100), APC anti-human/mouse pSYK (Tyr348) (eBioscience, \#17-9014-42), eFluor 660 anti-human Phospho-NFkB p65 (Ser529) (eBioscience, \#50-9863-42), APC anti-human Phospho-p38 MAPK (Thr180, Tyr182) (eBioscience, \#17-9078-42), eFluor 660 anti-human Phospho-IkB alpha (Ser32, Ser36) (eBioscience, \#50-9035-42), eFluor 660 anti-human Phospho-SRC (Tyr418) (eBioscience, \#50-9034-42), APC anti-human Phospho-ERK1/2 (Thr202, Tyr204) (eBioscience, \#17-9109-42), eFluor 450 anti-human Phospho-AKT1 (Ser473) (eBioscience, \#48-9715-
42), Alexa Fluor 647 anti-human Phospho-IRAK4 (Thr345/Ser346) (Cell Signaling, \#87995), PE antihuman CD369 (Clec7a, Dectin-1) (eBioscience, \#129856-42).

Real-time Quantitative Polymerase Chain Reaction (qPCR)

DCs were lysed in Trizol, and RNA extraction was performed as previously described [27]. cDNA synthesis was performed using the iScript ${ }^{\mathrm{TM}} \mathrm{cDNA}$ synthesis kit from Bio-Rad. Real-time qPCR was performed using SYBR Green. Gene expression was normalized over ribosomal 18S. Delta $\mathrm{Ct}$ method was applied to analyze the data. Primer pairs: IL23p19 FW 5'-GCAGATTCCAAGCCTCAGTC-3', RV 5'-TTCAACATATGCAGGTCCCA-3'; IL12p40 FW 5'-GGAGAGTCTGCCCATTGAGG-3', RV 5'-TCTTGGGTGGGTCAGGTTTG-3'; IL12p35 FW 5'-CCTCCACTGTGCTGGTTTTAT-3', RV 5'-TCAGCAACATGCTCCAGAAG-3'; 18S FW 5'-GTAACCCGTTGAACCCCATT-3', RV 5'-CCATCCAATCGGTAGTAGCG-3'.

\section{Enzyme-linked Immunosorbent Assay}

An equal number of monocyte-derived DCs (either long-term IL-15-exposed or controls) was matured in the presence of PGN, curdlan along with or without IL-15 for 24 hours in complete medium in triplicate or quadruplicate wells. For immature condition, DCs were cultured in complete medium alone. Supernatants were taken and directly used for ELISA without dilution. Similarly, for short term IL-15 exposure, IL-15 was added to DC cultures during only maturation with PGN or curdlan for 24 hours, and the supernatants were collected and used for ELISA without dilution. Human IL-23 ELISA kit was purchased from eBioscience (\#BMS2023$3)$. ELISA protocol was performed in accord with the manufacturer's guidelines. The plates were read on the Promega Glomax Multi Detection plate reader.

\section{DC: T Cell Coculture Assay}

Curdlan matured DCs $(50,000$ to 100,000 cells $)$ were cultured with Microbead selected allogenic total CD4+ T cells $(100,000$ cells $)$ for three days in complete medium, anti-CD3 $(1 \mu \mathrm{g} / \mathrm{ml})$. The cells were then stained for anti-IL-17A, anti-GM-CSF, anti-IFN-y and analyzed via FACSAriaIII. 


\section{Statistical Analyses}

Student's t-test or ANOVA was used where appropriate. GraphPad Prism 6 was used for the analyses. $* \mathrm{p}<0.05$, $* * \mathrm{p}<0.01, * * * \mathrm{p}<0.001$, ns not significant.

\section{RESULTS}

Effects of IL-15 on DC Differentiation, Maturation and Costimulatory Molecule Expression

To test the impacts of IL-15 on human dendritic cells, monocytes were differentiated into DCs with GM-CSF and IL-4 (50 ng/ml each). After five days of culture, more than $90 \%$ of the monocytes differentiated into DCs and upregulated CD11c and HLA-II (Fig. 1A). The number of DCs recovered from the IL-15+ cultures was slightly higher in many differentiation trials; however, the difference in the number of DCs between IL-15+ and control groups for long term IL-15 exposure cultures was not statistically significant (Fig. 1B). DCs were then matured with curdlan for 24 hours. Curdlan was used owing to its induction of Th17-polarizing cytokine production by DCs. For long term exposure, IL-15 was added into differentiation cultures along with GM-CSF and IL-4 and was also present during maturation. The control group did not contain IL-15. For short term IL-15 exposure, we added IL-15 only during maturation of DCs. DCs were then stained for MHCII, CD80 and CD86. Curdlan matured DCs upregulated MHCII, CD80 and CD86. Addition of IL-15 (long term exposure from the beginning of the differentiation or short term) did not result in statistically significant differences in HLA-II, CD80 or CD86 expression either in immature or mature state (Fig. 1C).

\section{Short- or Long-term IL-15 Exposure Negatively} Regulates Curdlan-induced IL-23 Production by DCs We tested the impacts of IL-15 cytokine exposure of human DCs on IL-23 production in two ways. First, DCs

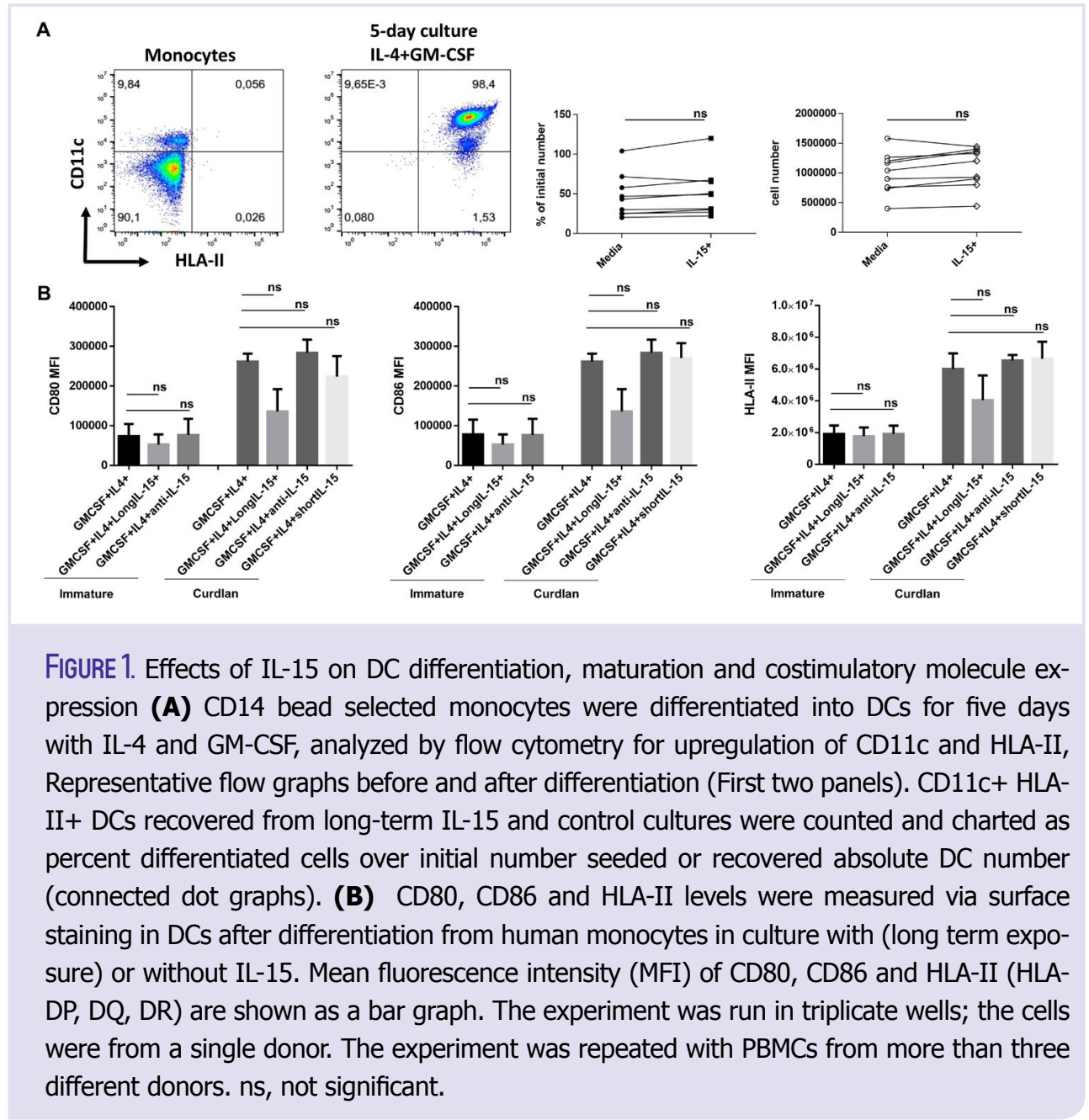


were differentiated from monocytes for five days in the

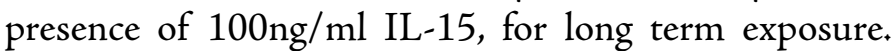
Then, they are matured with curdlan. Secondly, for short term exposure, IL-15 was added only during the maturation process, the last 24 hours. In both cases, IL-23 production was quantified from supernatants and was significantly reduced in cultures where IL-15 was added (Fig. 2A-B). Next, we quantified the mRNA expression of IL12A, IL23A and IL-12B. In long term exposure, IL12B and IL12A levels were significantly downregulated in mature DCs, suggesting downregulation of both IL-12 and IL-23 (Fig. 2C). In short term exposure, IL23A expression was reduced significantly, whereas IL12B and IL12A were up and comparable, respectively, consistent with downregulation of IL-23 protein (Fig.
2D). Collectively, these results suggest that IL-15 may negatively regulate IL-23 production by human DCs.

\section{IL-15 Exposure Downregulates Surface Dectin-1}

Receptor Expression and Effects Signaling in DCs

Since curdlan matured DCs showed a significant reduction in IL-23 production, but not PGN matured or immature DCs, we reasoned that receptors for curdlan recognition might be negatively regulated by IL-15 exposure. Thus, we quantified Dectin-1 (Clec7a) receptor levels on the surface of DCs by surface staining. Indeed, IL15 exposed immature DCs expressed significantly lower levels of Dectin-1 receptor compared to control DCs (Fig. 3A, B). Importantly, consistent with the reduced levels of Dectin-1 receptor, signalling downstream of the

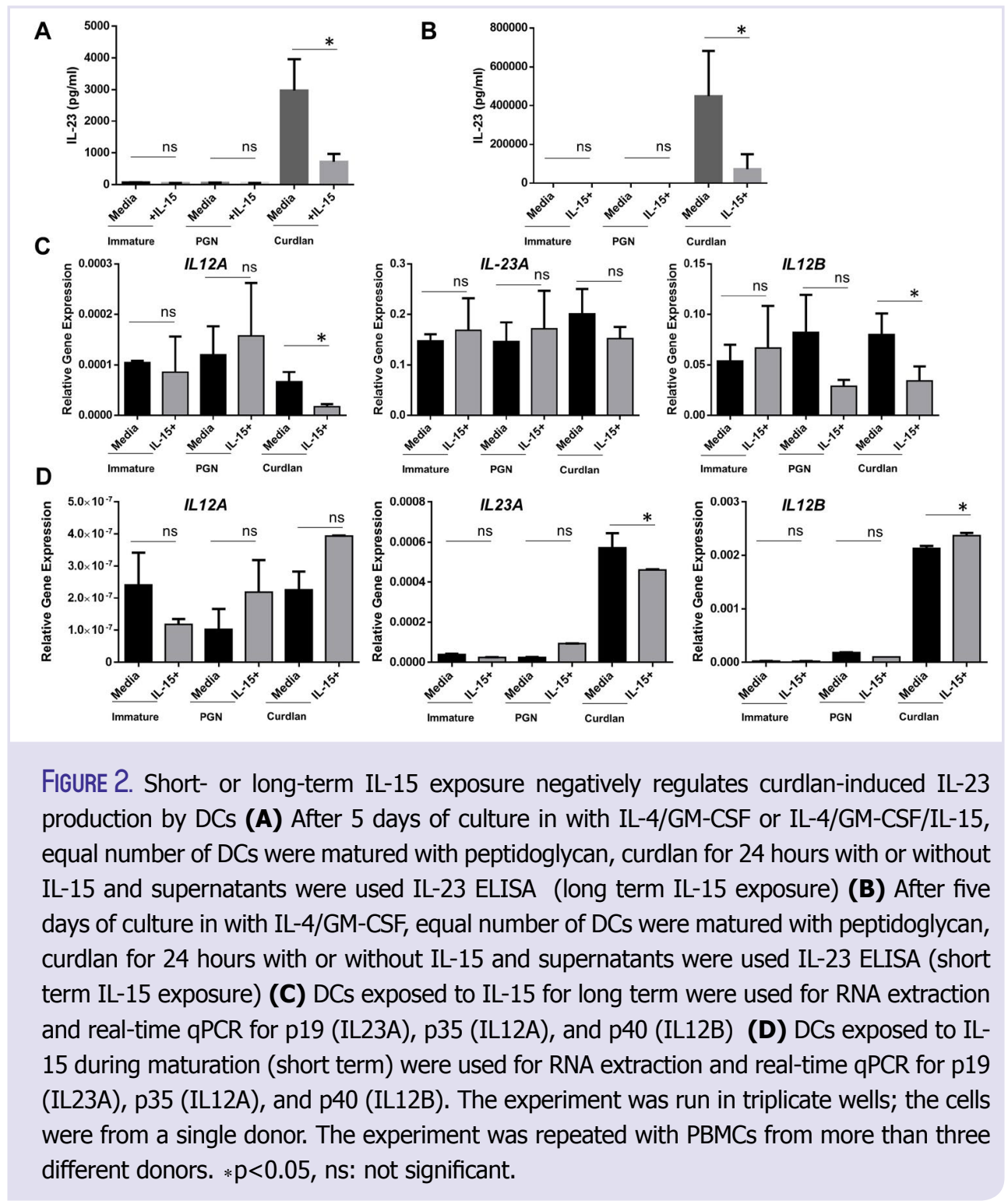


Dectin-1 receptor was also altered. Phosphorylation of ERK1/2, AKT, IKBA and NF-kB p65 was significantly reduced, and $\mathrm{p} 38$ was increased in DCs generated in the presence of IL-15 compared to control DCs (Fig. 3C). The changes in SRC and IRAK4 were not statistically significant. These results suggest that reduced IL-23 production by DCs generated in the presence of IL-15 may partly be explained by the decrease in Dectin- 1 receptor levels and signalling.

IL-15-exposed DCs Favor Th1 rather than Th17 in Mixed Leukocyte Reaction Cultures

To test whether the reduction in IL-23 by IL-15 exposed dendritic cells has functional consequences in polarizing CD4+ T cells, we cocultured allogeneic $T$ cells with dendritic cells generated in the presence or absence of IL-15 and matured with curdlan (Fig. 4). Consistent with the reduction in IL-23, cocultures of allogeneic $T$ cells with IL-15-exposed dendritic cells resulted in less IL-17A, and more INF- $\gamma$ production by $\mathrm{T}$ cells compared with control dendritic cells not exposed to IL-15. Importantly,
GM-CSF production by $T$ cells was not impacted. These results support our data that IL-15 exposure of DCs may reprogram them away from Th17-polarizing phenotype.

\section{DISCUSSION}

In this study, we show that human dendritic cells exposed to IL-15 have lower Dectin-1 receptor expression. Thus, curdlan-mediated maturation results in reduced IL-23 production and, thus, reduced IL-17A production by T cells. Our results collectively reveal that IL-15 may act as a negative regulator of human Th17 response.

Elevated IL-15 has been reported in various intestinal pathologies [28]. In both celiac and IBD patients, IL-15 levels and the cellular sources of IL-15 have been shown to be increased in the intestine [29-31]. In fact, some SNP variants of $I 115$ have been identified as risk factors for IBD [32]. In the murine models, IL-15 was shown to negatively regulate Th17 cells. This was demonstrated by adding recombinant IL-15 to Th17 cultures ex vivo, or by transferring $T$ cells into IL-15-deficient mice [7, 19,
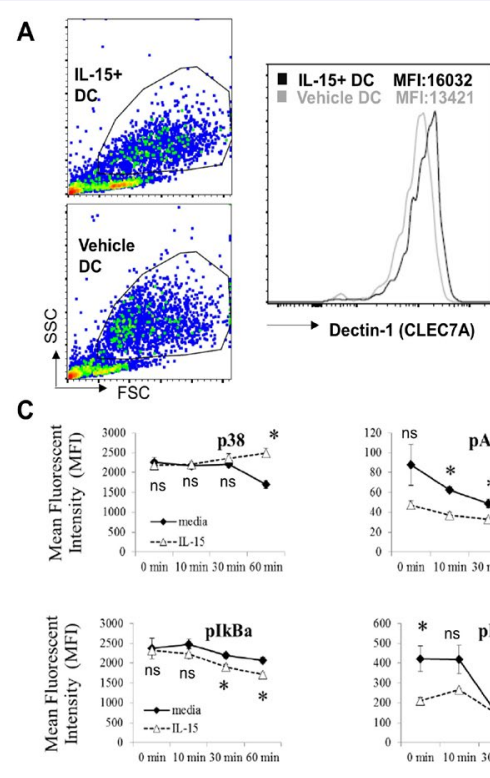

B
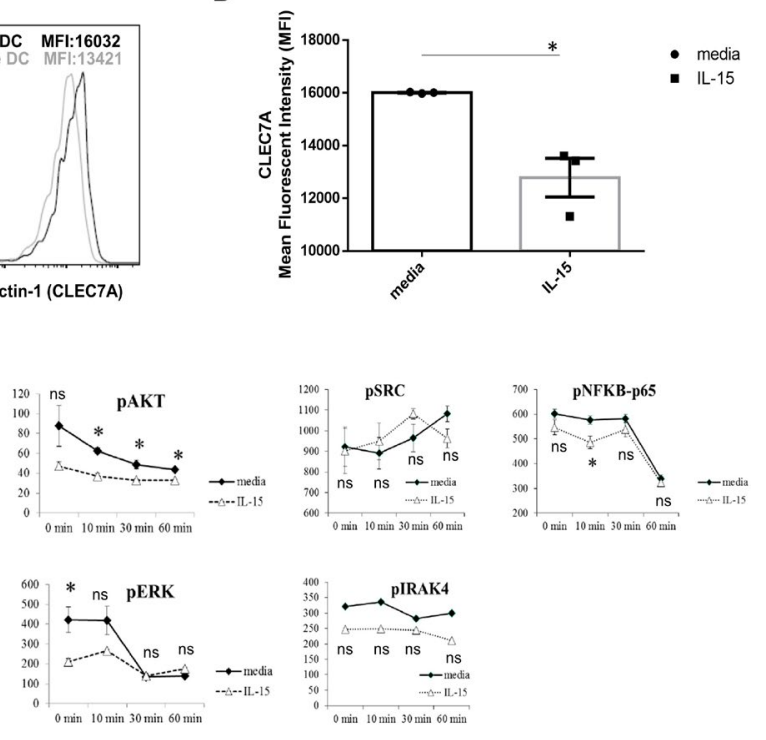

FIGURE 3. IL-15 exposure downregulates surface Dectin-1 receptor expression and impacts signalling in DCs (A) After five days of culture in with IL-4/GM-CSF or IL-4/GM-CSF/IL-15 DCs were surface stained for $\mathrm{Clec} 7$ (Dectin-1) and a representative flow graph and (B) quantification of mean fluorescent intensity (MFI) as bar graph are presented. The experiment was run in triplicate wells and a representative result from a single donor was shown, the experiment was repeated with four different donors. (C) DCs from " $A$ " were stimulated with curdlan $(50 \mu \mathrm{g} / \mathrm{ml})$ and phosphorylation of p38, AKT, SRC, NFKB p65, IkBa, ERK1/2 and IRAK4 was measured by phospho-flow assay. A representative result from PBMCs of a single donor was charted. ${ }^{*} \mathrm{p}<0.05$, ns: not significant. 


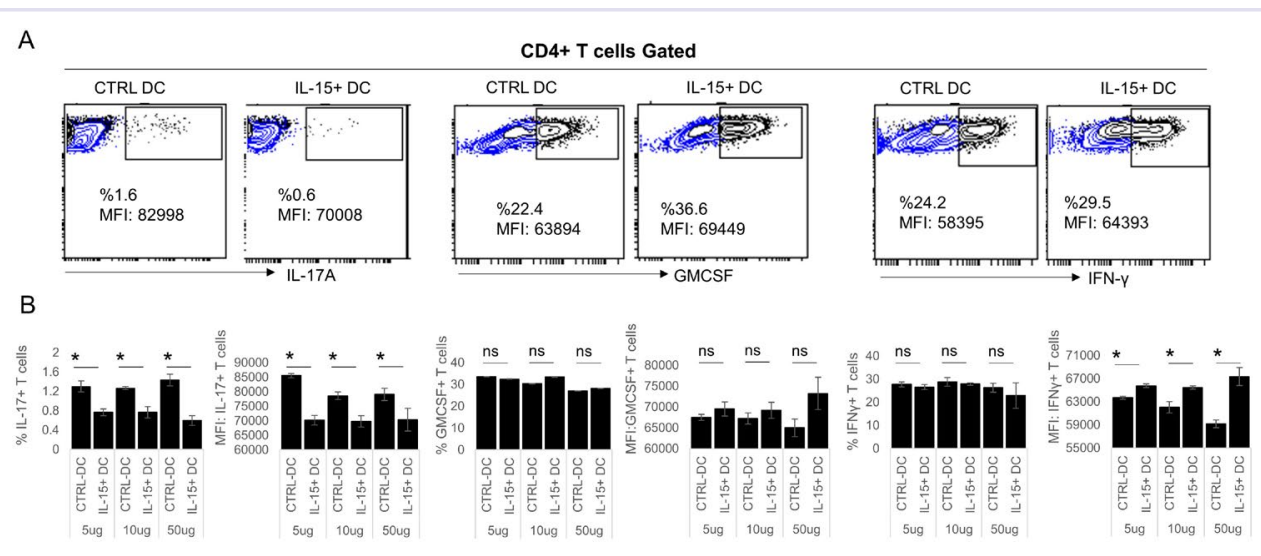

FIGURE 4. IL-15-exposed DCs augments Th1 rather than Th17 in MLR reaction. Curdlan matured DCs after differentiation from human monocytes in culture with (long term exposure) or without IL-15 were co-cultured with CD4 bead selected allogeneic $T$ cells for three days. After five hours of PMA/Ionomycin/Golgi Plug stimulation Il-17A, GM-CSF and IFN- $y$ levels were measured by intracellular cytokine staining. A representative flow graph and quantified bar graphs were shown for a single donor. The experiment was repeated with two additional donor-derived DCs. ${ }^{*} p<0.05$, ns: not significant.

21]. Additionally, higher Th17 cells have been reported in IL-15-/- mice $[19,20,22,23]$. These findings have been supported by the observations of exacerbated disease in murine models of colitis and multiple sclerosis in Il15-/- mice $[19,22,23]$. In addition to the direct effects of IL-15 on T cells, IL-15/IL-15R signalling on murine DCs was shown to be critical for the production of IL-12p70, thus possibly IL-23 [33]. On the other hand, other studies showed that neutralization of IL-15 in CD4+ T cell transfer colitis improved pathology, whereas in DSS or TNBS-induced colitis IL-15 neutralization did not confer protection, despite the reduction of inflammatory cells and reduced inflammatory cytokines $[34,35]$. These results point to the context-dependent role of IL-15.

Impacts of IL-15 on human monocyte-derived DCs using select maturation ligands have been studied by Harris et al., and Anguille et al. [26, 36, 37]. In the previous two papers by Harris et al., the authors differentiated DCs from human monocytes with GM-CSF and IL-15 together in culture. In their first report, DCs were differentiated with IL-15 and GM-CSF and loaded with wheat gliadin, whereas, in the second report, DCs were matured with TLR2/1, TLR3 and TLR4 agonists, Pam3Csk4, poly I:C and LPS, respectively [26, 36, 37]. Both studies have demonstrated elevated IL-6, IL-1B and IL-23 production by DCs, and consequently supported Th17 cells in allogeneic cultures. Anguille et al. compared the DCs generated with IL-4 and GM-CSF together to those generated with IL-15 and GM-CSF after maturation with TNF-a, IL1 $\beta$, IL- 6 and PGE2. Similarly, IL-1B and IL- 6 were elevated in DCs generated with IL-15 and GM-CSF compared with DCs generated in the presence of IL-4 and GM-CSF. In none of these papers did the authors use a fungal PAMP for the maturation of DCs. Our findings that IL-15 exposure results in reduction in the IL-23 and the allogenic Th17 response contrast with these previous reports, however, are in line with murine findings that IL-15 is a negative regulator of Th17 responses [7,19-23]. The reasons for these divergent results may be manifold. Firstly, Harris et al. and Anguille et al. studies replaced IL-4 with GMCSF whereas, in our studies, IL-4 was always present in all DC cultures. Secondly, in those papers, Dectin-1 levels have not been measured $[26,36,37]$. Lastly, curdlan, as a fungal PAMP, has not been used to mature the DCs. In fact, the effect we observed was specific to curdlan and was not detected when peptidoglycan was used.

Our results collectively suggest that IL-15 exposure of human monocyte-derived DCs may have a negative impact on fungal PAMP induced -IL-23 production and, subsequent Th17 response. Therefore, Th17 response may be regulated by the bioavailability of IL-15 in vivo.

Ethics Committee Approval: Erciyes University, \#2015/521. 
Conflict of Interest: No conflict of interest was declared by the authors.

Financial Disclosure: The authors declared that this study has received no financial support.

Funding: This work was supported in part by the Turkish Scientific and Technological Research Council (TUBITAK) and BIDEB grants [215S725, 315S315 and 116C008]; and partly by Erciyes University BAP grant [TOA-2016-6130] and TCD-2019-8751.

Authorship Contributions: Concept - $A E, H C, H D A$; Design - $A E$, $\mathrm{HC}$, HDA; Supervision - AE; Materials - EY, MK, SE; Data collection and/or processing - SE, MK, EY, FZO, ZBA, YH, AB, TNG, AE; Analysis and/or interpretation - $A E$, $F Z O, S E$; Writing $-A E$; Critical review $A E$, FZO, SE, ZBA, YH, AB, TNG, EY, MK, HDA, HC.

\section{REFERENCES}

1. Waldmann TA. Interleukin-15 in the treatment of cancer. Expert Rev Clin Immunol 2014;10:1689-701. [CrossRef]

2. Waldmann TA. The Biology of IL-15: Implications for Cancer Therapy and the Treatment of Autoimmune Disorders. J Investig Dermatology Symp Proc 2013;16:S28-30. [CrossRef]

3. Croce M, Orengo AM, Azzarone B, Ferrini S. Immunotherapeutic applications of IL-15. Immunotherapy 2012;4:957-69. [CrossRef]

4. Grabstein K, Eisenman J, Shanebeck K, Rauch C, Srinivasan S, Fung V, et al. Cloning of a $\mathrm{T}$ cell growth factor that interacts with the beta chain of the interleukin-2 receptor. Science 1994;264:965-8. [CrossRef]

5. Burton JD, Bamford RN, Peters C, Grant AJ, Kurys G, Goldman CK, et al. A lymphokine, provisionally designated interleukin $\mathrm{T}$ and produced by a human adult T-cell leukemia line, stimulates T-cell proliferation and the induction of lymphokine-activated killer cells. Proc Natl Acad Sci U S A 1994;91:4935-9. [CrossRef]

6. Bamford RN, Battiata AP, Burton JD, Sharma H, Waldmann TA. Interleukin (IL) 15/IL-T production by the adult T-cell leukemia cell line HuT-102 is associated with a human T-cell lymphotrophic virus type I region /IL-15 fusion message that lacks many upstream AUGs that normally attenuates IL-15 mRNA translation. Proc Natl Acad Sci U S A 1996;93:2897-902. [CrossRef]

7. Waickman AT, Ligons DL, Hwang S, Park JY, Lazarevic V, Sato N, et al. CD4 effector T cell differentiation is controlled by IL-15 that is expressed and presented in trans. Cytokine 2017;99:266-74. [CrossRef]

8. Giri JG, Kumaki S, Ahdieh M, Friend DJ, Loomis A, Shanebeck K, et al. Identification and cloning of a novel IL-15 binding protein that is structurally related to the alpha chain of the IL-2 receptor. EMBO J 1995;14:3654-63. [CrossRef]

9. Spolski R, Gromer D, Leonard WJ. The yc family of cytokines: finetuning signals from IL-2 and IL-21 in the regulation of the immune response. F1000Res 2017;6:1872. [CrossRef]

10. Dubois S, Mariner J, Waldmann TA, Tagaya Y. IL-15Ra Recycles and Presents IL-15 In trans to Neighboring Cells. Immunity 2002;17:53747. [CrossRef]

11. Zhang X, Sun S, Hwang I, Tough DF, Sprent J. Potent and selective stimulation of memory-phenotype CD8+ T cells in vivo by IL-15. Immunity 1998;8:591-9. [CrossRef]

12. Carson WE, Giri JG, Lindemann MJ, Linett ML, Ahdieh M, Paxton $\mathrm{R}$, et al. Interleukin (IL) 15 is a novel cytokine that activates human natural killer cells via components of the IL-2 receptor. J Exp Med 1994;180:1395-403. [CrossRef]

13. Oppmann B, Lesley R, Blom B, Timans JC, Xu Y, Hunte B, et al.
Novel p19 protein engages IL-12p40 to form a cytokine, IL-23, with biological activities similar as well as distinct from IL-12. Immunity 2000;13:715-25. [CrossRef]

14. Eken A, Singh AK, Oukka M. Interleukin 23 in Crohn's disease. Inflamm Bowel Dis 2014;20:587-95. [CrossRef]

15. Gaffen SL, Jain R, Garg A V, Cua DJ. The IL-23-IL-17 immune axis: from mechanisms to therapeutic testing. Nat Rev Immunol 2014;14:585-600. [CrossRef]

16. Patel DD, Kuchroo VK. Th17 Cell Pathway in Human Immunity: Lessons from Genetics and Therapeutic Interventions. Immunity 2015;43:1040-51. [CrossRef]

17. Korn T, Bettelli E, Oukka M, Kuchroo VK. IL-17 and Th17 Cells. Annu Rev Immunol 2009;27:485-517. [CrossRef]

18. Zúñiga LA, Jain R, Haines C, Cua DJ. Th17 cell development: from the cradle to the grave. Immunol Rev 2013;252:78-88. [CrossRef]

19. Pandiyan P, Yang X-P, Saravanamuthu SS, Zheng L, Ishihara S, O'Shea JJ, et al. The role of IL-15 in activating STAT5 and fine-tuning IL-17A production in CD4 T lymphocytes. J Immunol 2012;189:4237-46.

20. Yu H, Sui Y, Wang Y, Sato N, Frey B, Xia Z, et al. Interleukin-15 Constrains Mucosal $\mathrm{T}$ Helper 17 Cell Generation: Influence of Mononuclear Phagocytes. Unutmaz D, editor. PLoS One 2015;10:e0143001. [CrossRef]

21. Laurence A, Tato CM, Davidson TS, Kanno Y, Chen Z, Yao Z, et al. Interleukin-2 Signaling via STAT5 Constrains T Helper 17 Cell Generation. Immunity 2007;26:371-81. [CrossRef]

22. Tosiek MJ, Fiette L, El Daker S, Eberl G, Freitas AA. IL-15-dependent balance between Foxp3 and RORyt expression impacts inflammatory bowel disease. Nat Commun 2016;7:10888. [CrossRef]

23. Tosiek M, Fiette L, Freitas A. IL-15 deficiency promotes accelerated colitis upon expansion of CD4+ T cells (P1231). J Immunol 2013;190:188.18.

24. Anguille S, Smits ELJM, Cools N, Goossens H, Berneman ZN, Van Tendeloo VFI. Short-term cultured, interleukin-15 differentiated dendritic cells have potent immunostimulatory properties. J Transl Med 2009;7:109. [CrossRef]

25. Harris KM. Monocytes differentiated with GM-CSF and IL-15 initiate Th17 and Th1 responses that are contact-dependent and mediated by IL-15. J Leukoc Biol 2011;90:727-34. [CrossRef]

26. Harris KM, Fasano A, Mann DL. Monocytes differentiated with IL15 support Th17 and Th1 responses to wheat gliadin: implications for celiac disease. Clin Immunol. 2010;135:430-9. [CrossRef]

27. Eken A, Singh AK, Treuting PM, Oukka M. IL-23R+ innate lymphoid cells induce colitis via interleukin-22-dependent mechanism. Mucosal Immunol 2014;7:143-54. [CrossRef]

28. Pagliari D, Cianci R, Frosali S, Landolfi R, Cammarota G, Newton EE, et al. The role of IL-15 in gastrointestinal diseases: a bridge between innate and adaptive immune response. Cytokine Growth Factor Rev 2013;24:455-66. [CrossRef]

29. Sakai T, Kusugami K, Nishimura H, Ando T, Yamaguchi T, Ohsuga M, et al. Interleukin 15 activity in the rectal mucosa of inflammatory bowel disease. Gastroenterology 1998;114:1237-43. [CrossRef]

30. Waldmann TA, Tagaya Y. The Multifaceted Regulation Of Interleukin-15 Expression And The Role Of This Cytokine In Nk Cell Differentiation And Host Response To Intracellular Pathogens. Annu Rev Immunol 1999;17:19-49. [CrossRef]

31. Nishiwaki T, Ina K, Goto H, Watanabe O, Tsuzuki T, Furuta R, et al. Possible involvement of the interleukin-15 and interleukin-15 receptor system in a heightened state of lamina propria B cell activation and differentiation in patients with inflammatory bowel disease. J Gastroen- 
terol 2005;40:128-36. [CrossRef]

32. Yamamoto-Furusho JK, De-León-Rendón JL, Alvarez-León E, Valdivia-Eziquio M, Obil-Chavarría C, Vargas-Alarcón G. Association of the interleukin 15 (IL-15) gene polymorphisms with the risk of developing ulcerative colitis in Mexican individuals. Mol Biol Rep 2014;41:21716. [CrossRef]

33. Ohteki T, Suzue K, Maki C, Ota T, Koyasu S. Critical role of IL-15IL-15R for antigen-presenting cell functions in the innate immune response. Nat Immunol 2001;2:1138-43. [CrossRef]

34. Jiang W, Wang X, Zeng B, Liu L, Tardivel A, Wei H, et al. Recognition of gut microbiota by NOD2 is essential for the homeostasis of intestinal intraepithelial lymphocytes. J Exp Med 2013;210:2465-76. [CrossRef]

35. Obermeier F, Hausmann M, Kellermeier S, Kiessling S, Strauch UG, Duitman E, et al. IL-15 protects intestinal epithelial cells. Eur J Immunol 2006;36:2691-9. [CrossRef]

36. Harris KM. Monocytes differentiated with GM-CSF and IL-15 initiate Th17 and Th1 responses that are contact-dependent and mediated by IL-15. J Leukoc Biol 2011;90:727-34. [CrossRef]

37. Anguille S, Smits ELJM, Cools N, Goossens H, Berneman ZN, Van Tendeloo VFI. Short-term cultured, interleukin-15 differentiated dendritic cells have potent immunostimulatory properties. J Transl Med 2009;7:109. [CrossRef] 